\section{Genealogia do teatro de improviso em Portugal: as sementes lançadas pela «geração sem fronteiras» dos anos 90}

\author{
ZECA CARVALHO \& GUSTAVO VICENTE
}

Despite the late consolidation of improvisation theatre in the country, the Portuguese artistic scene has seen the emergence in the last two decades of several impro companies with different approaches - many of them acquiring significant recognition among the public. However, the mapping of this practice and its relationship with the historical-cultural framework with which it is necessarily linked was never done before. This article contributes to fill this gap, not only tracing its genealogy in the context of contemporary history of the performing arts in Portugal, but also in the wider context of Portuguese socio-cultural development since the Revolution of April 25, 1974. More specifically, the research in which this article is based upon allowed us to identify a significant correlation between the process of theatrical renovation initiated by the generation of the 1990s and the precursors of this genre in Portugal. In this context, it stands out the role of Companhia do Chapitô, which inspired and provided the technical bases for many of the actors who later would dedicate themselves to the development of impro theatre. Following the genealogy review of this genre in Portugal, this article also contributes to the reflection on the nature of the dialogue that is established between the practice of impro and the cultural and political framework in which it manifests itself.

IMPROV THEATER / IMPROVISATTON / BODY / PORTUGUESE "GENERATION WITHOUT BORDERS" / 1990 S GENERATION

INTRODUCุÃO

Frequentemente designado pelas abreviaturas impro ou improv ${ }^{1}$, o teatro de improviso é hoje amplamente praticado por coletivos artísticos, instituições educacionais e organizações de produção cultural um pouco por

Como explica Dudeck (2013), a preferência pelo termo «impro» no Reino Unido e por «improv» na América do Norte deve-se a uma questão fonética, sem que as abreviaturas denotem distinções estilísticas. todo o mundo. Este género teatral emergiu, de acordo com Swiboda (2018), a partir das experimentações realizadas no final dos anos 50 pelo britânico Keith Johnstone, que culminaram na criação do teatro-desporto: uma forma teatral híbrida em que equipas de jogadores-performers competem entre si por meio de cenas de curta duração, para fornecer as melhores respostas aos desafios propostos pela audiência durante a performance. A partir da década de 1960, segundo Fotis (2012), vários grupos teatrais norte-americanos alargaram as possibilidades do sistema criado por Johnstone para tornar possível a criação espontânea de histórias de formato longo, apresentadas em espetáculos performatizados por múltiplos improvisadores na ausência de roteiros predeterminados.

Para Dudeck (2013), motivado pela busca de novas possibilidades de relação com a audiência, Johnstone dedicou-se a desenvolver métodos de improvisação teatral para potenciar a ação espontânea por parte dos performers e um comportamento de maior cumplicidade por parte do público, promovendo a construção de situações cénicas nascidas do contexto imediato desse encontro. $\mathrm{Na}$ base da proposta do encenador e pedagogo britânico, está a premissa de que qualquer pessoa se encontra apta a improvisar e actuar com efectividade diante de uma plateia, quando libertada da obrigação de brilhar em palco (Johnstone, 1990). Assim, por intermédio da improvisação, vista não como processo preparatório para a criação artística, mas como espetáculo per se construído juntamente com o público, o teatro torna-se um veículo de «revalorização da espontaneidade, da escuta, do coletivo, da coautoria entre público e atores, da valorização do momento presente na arte de criar e recriar histórias coletivamente no aqui e agora» (Muniz, 2015: 32).

Dado o enquadramento histórico de desenvolvimento das artes performativas em Portugal, o sistema erigido por Johnstone desabrolhou no país apenas no ano 200o, quando três atores da Companhia do Chapitô fundaram o grupo Commedia a la Carte para encenar o primeiro espetáculo teatral completamente improvisado em terras lusitanas. Desde então, a cena portuguesa tem visto surgir diversos grupos de impro com abordagens diferenciadas - muitos deles conquistando projecção assinalável junto de um público, também este, cada vez mais interessado no género. ${ }^{2}$

Em meados de 2019, eram dez os coletivos teatrais dedicados ao teatro de improviso em Portugal, dos quais a maioria situada no eixo Lisboa-Sintra: Commedia a la Carte, Os Improváveis, Instantâneos, ImprovFX, Cardume, Improvisto, Sem Rede, Lilimprov, Jokebox e 4Misfits. Em entrevista, Marco Graça, dos Instantâneos, menciona ainda a existência de outros grupos portugueses de teatro de improviso extintos por volta de 2015 ou 2016: O Cão Comeu o Guião, Café Improv, Work Improgress, Os Comicídio e Quantos Queres. 
A participação em festivais internacionais de improvisação tornou-se, entretanto, frequente; e ao nível da organização, Portugal conta, hoje, com dois festivais dedicados ao teatro de improviso. ${ }^{3}$

Não obstante a dinâmica de expansão do teatro de improviso, para Ortalli (2014), o género encontra-se ainda em fase de incubação, mantendo em aberto diversos horizontes de exploração, nomeadamente aqueles que vierem a ser criados no diálogo entre a prática e a investigação na esfera dos estudos artísticos. Em Portugal, a investigação nesta matéria é ainda incipiente, tornando-se urgente mapear as origens do movimento impro em Portugal em face do enquadramento histórico que lhe serviu de base - principalmente aquele que decorreu na sequência da abertura possibilitada pelo 25 de Abril. Neste artigo, refletimos em particular sobre a influência da geração de criadores da década de 1990, a qual deu origem a uma mudança significativa na maneira de se fazer e pensar as artes performativas em Portugal.

Para a nossa pesquisa, baseámo-nos no estudo de três coletivos portugueses, selecionados pela sua relevância histórica e produção artística atual: Commedia a la Carte, Os Improváveis e Instantâneos. Fundados nos anos 2000, 2008 e 2011, respetivamente, estes três grupos são os pioneiros do género impro que ainda se encontram em atividade no país, e a partir dos quais é possível aferir o percurso do teatro de improviso em Portugal. ${ }^{4}$

\section{AS FRONTEIRAS ABERTAS PELA GERAÇÃO DE 1990}

A época que encerrou as quase cinco décadas de ditadura deixou marcas tão profundas nos Portugueses que, ainda hoje, é tomada como ponto de partida para qualquer reflexão sobre Portugal contemporâneo. As cicatrizes deixadas pelos fantasmas da censura, da repressão, da pobreza generalizada, do isolamento cultural, dos ideais imperialistas e das consequentes guerras coloniais continuam a ser alvo de vários estudos, principalmente aqueles que procuram dar um tom identitário ao que pode significar ser-se português hoje em dia. O livro Portugal: o medo de

O Festival Espontâneo, dirigido pelo grupo Instantâneos, em Sintra, e o Festival Noites Imprevistas, produzido em Queluz pelos coletivos Improvisto e Cardume.

4 Em conformidade com a abordagem de multimétodos para a recolha e a interpretação de material empírico, na investigacão foram antepostas duas possibilidades de coleta de dados junto dos coletivos considerados para estudos de casos - a observação simples estruturada $e$ as entrevistas semiestruturadas (Sampieri/Collado/Lucio, 2015) -, às quais foram aditadas duas técnicas de apoio: os registos textuais em diário de campo e os registos fotográficos. Os dados foram coletados no período compreendido entre agosto de 2018 e junho de 2019.

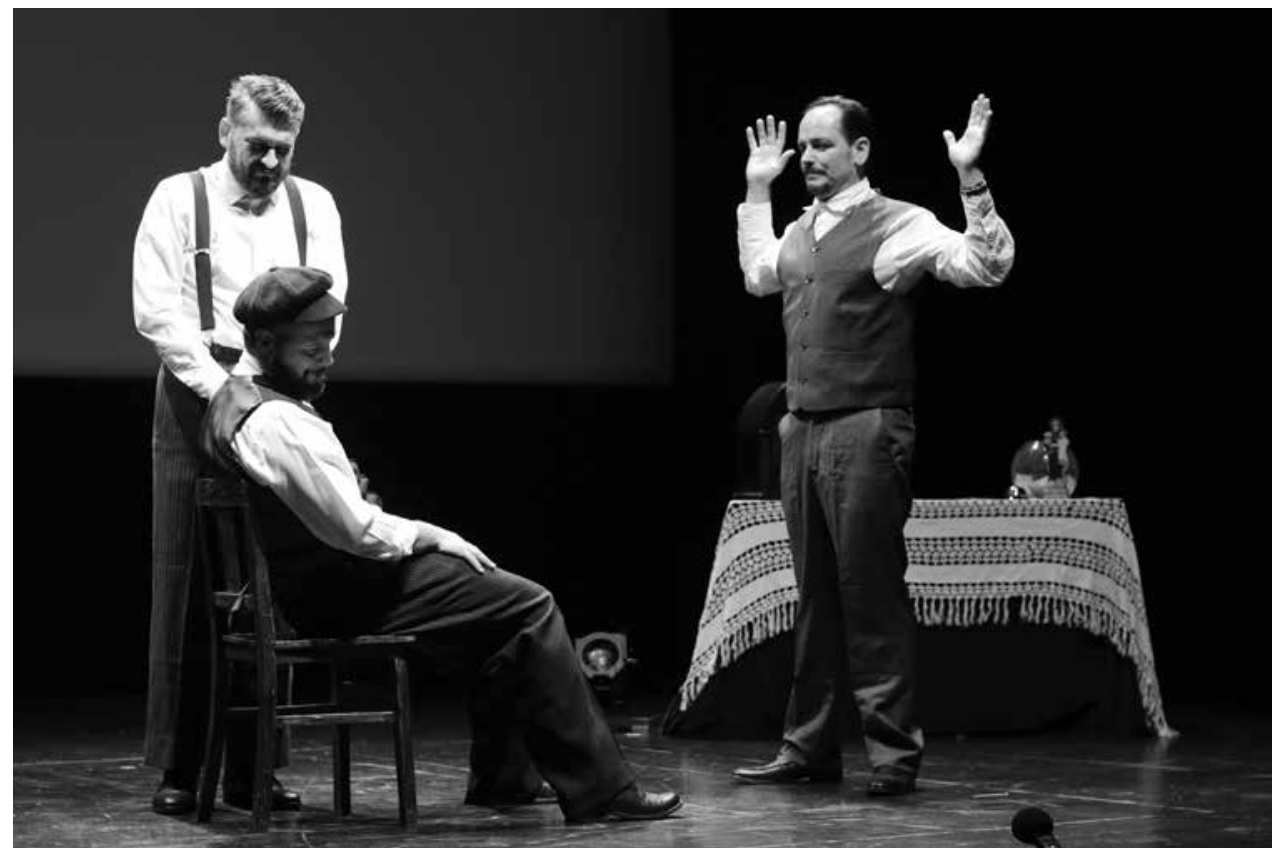

EVARISTO, CRIAÇÃO COLETIVA, ENC. MARCO GRAÇA, INSTANTÂNEOS, 2018 (MARCO GRAÇA, MARCO MARTIN E RICARDO SOARES), [F] ZECA CARVALHO

existir de José Gil (2007) é exemplo paradigmático desta necessidade de compreender o legado afetivo desse período, e a síndrome da «não inscrição», que o autor revela no mesmo texto, o traço distintivo que, de forma mais pungente, tem reverberado na consciência coletiva dos Portugueses após a ditadura. ${ }^{5}$ Este apagamento foi cultivado ao longo de meio século de controlo apertado pelo sistema de censura, especialmente a que recaía sobre a iniciativa artística, votando o país a um estado de hermetismo cultural que foi corroendo a vontade de afirmação dos Portugueses na esfera pública. Como recorda Gil (2007: 25), durante o salazarismo, «a arte é uma questão privada. Não entra na vida, não transforma as existências individuais».

No campo das artes performativas, que se apoia no encontro ao vivo, que se abre naturalmente ao estabelecimento de comunidades (mesmo

5 Gil (2007: 17) recorre a este termo para dar conta da incapacidade atávica dos Portugueses para se afrmarem no espaço público, a qual cocorre do processo de infantilização - para usar a sua expressão - promovido pelo regime ditatorial ao longo de 48 anos: «A não inscricãão não data de agora, é um velho hábito que vem sobretudo da recusa imposta ao indivíduo de se inscrever. Porque inscrever implica acção, afirmação, decisão com as quais o indivíduo conquista autonomia e sentido para a sua existência. Foi o salazarismo que nos ensinou a irresponsabilidade - reduzindo-nos a crianças, crianças grandes, adultos infantilizados.» 
que provisórias) e se manifesta na predisposição popular para se juntar em assembleia - mesmo que por razões que parecem pertencer ao domínio estrito da estética -, a sua contenção foi alvo de redobrada atenção por parte do regime fascista. O teatro foi, desta forma, «levado» a cingir-se às suas manifestações de teor mais comercial (dentro das quais o teatro de revista ocupou um lugar de destaque); e a dança, que nunca teve grande tradição em Portugal, foi quase sempre ignorada enquanto género artístico, ficando reduzida essencialmente às suas expressões folclóricas (Vicente, 2017a) - que o regime tentou elevar ao estatuto de ícones culturais ao serviço da propaganda nacionalista. ${ }^{6}$

Com a Revolução dos Cravos, como ficou conhecida a insurreição militar do 25 de Abril, os Portugueses centraram-se na reconstrução de um país empobrecido, pouco instruído e assoberbado pelo espectro de possibilidades de afirmação política e sociocultural a que agora tinha acesso. Não foi de estranhar, por isso, que, em sintonia com o clima pós-revolucionário, se viram erguer uma série de companhias que ostentavam um cariz ideológico bem vincado - constituindo, no seu conjunto, aquilo que viria a ser conhecido como o teatro independente. ${ }^{7}$ Como destaca Brilhante (2009: 127), a revolução revigorara «a urgência de fazer teatro, de pôr em cena os textos e os autores proibidos, de ganhar um público que se afastara das salas de teatro e [...] afirmar diferenças estéticas e artísticas para concretizar sonhos de teatro adiados». Apesar das diferenças ao nível das linguagens artísticas e contextos de implementação, as várias companhias do teatro independente procuraram, acima de tudo, dar corpo a uma voz coletiva virada para a construção de um futuro democrático.

Os anos 80 trataram, no entanto, de aplacar este entusiasmo coletivista, nomeadamente por efeito da crise ideológica que acompanhava a cultura mercantilista que já dominava a maioria das democracias ocidentais, depondo muitas das ilusões de autodeterminação dos Portugueses,

6 Em 1940, o governo salazarista, por iniciativa de António Ferro - chefe da propaganda e politica cultural do Estado Novo - apoiou a fundação de uma companhia de dança «moderna» porao trabalho que os Ballets Russes tinham espoletado no plano internacional, mas, na prática, não chegou a produzir mais do que formas improvisadas de dança folclórica, projetando-se sob o signo do nacionalismo que o regime ditava e não a partir de um desejo de questionasob o signo do nacionalismo que o regime
mento e renovaçãa cultural (Vicente, 2017b)

7 Tal como assinalado por Rui Pina Coelho, as companhias que deram corpo a este movimento reivindicavam a sua «independência face à intromissão do Estado nas escolhas repertoriais» (Coelho vindicavam a sua «independencia face a intromissão do Estado nas escolhas repertoriais» (Coelho,
2017: 15), deste modo marcando uma posição de salvaguarda da liberdade artística dos seus criadores. Foi deste movimento que saíram vários coletivos essenciais ao percurso teatral português, dos quais se destacam o Teatro Experimental de Cascais, A Comuna - Teatro de Pesquisa, Teatro da Cornucópia, Seiva Trupe, Teatro O Bando, A Barraca e o Novo Grupo - Teatro Aberto. que, nessa altura, começavam a perceber que seguiam um rumo que não haviam previsto e que não conseguiam controlar completamente (Vicente, 2017b). Entretanto, incitados pela abertura ao exterior catapultada pela adesão à Comunidade Económica Europeia em 1986 - que acelerou o contacto com a prática artística internacional mais inovadora -, a década de 1990 viu nascer uma nova geração de criadores que veio posicionar-se de forma alternativa à dominância estética do teatro independente. Para isso, muito contribuiu o movimento da Nova Dança Portuguesa, iniciado anos antes com o despontar de uma vaga de novos coreógrafos que, por seus próprios meios e de forma quase autodidata, veio fazer estremecer a cena portuguesa com a introdução de abordagens experimentais que deram origem a novos léxicos corporais e dispositivos cénicos alternativos.

Este conjunto de criadores de teatro, a que Vicente (2012) chamou «geração sem fronteiras», assumiu uma nova postura no panorama das artes performativas em Portugal, traduzida no desejo de dar uma visão de si próprios e do mundo e na preocupação de inscrever os seus projectos na esfera subjetiva da contemporaneidade. Este desejo deu origem a muitas e diferenciadas propostas, marcadas pelo afastamento do logocentrismo que dominara a produção do teatro independente; por uma maior ênfase dada à corporalidade e pela criação de novos discursos cénicos, menos apoiados nas diferenças de género artístico e mais na transversalidade de linguagens e vocabulários estéticos em palco. Foi esta geração que marcou a passagem de um teatro apoiado no poder dialético do texto para «educar» o público para um teatro assente na «vivência» do hic et nunc do espetáculo, estabelecendo, dessa forma, novas relações de cumplicidade com os espectadores e abordando as inquietações e os desafios do seu próprio tempo.

Desta pluralidade criativa surgiram companhias como a Garagem, ligada à investigação de novas formas de escrita para teatro; o Olho, que, sediando-se no espaço alternativo do Ginjal $^{8}$, se apoiou no caráter laboratorial e na transversalidade de meios trazida da performance art; o Teatro Meridional, numa fase inicial dedicado ao domínio das técnicas da

8 Em 1994, a companhia sediou-se no Cais do Ginjal - um armazém abandonado em Almada, na Margem Sul do Tejo, Margem Sul do Tejo, que ficaria conhecido como o Espaço Ginjal. Este espaço permitiu que o
grupo encontrasse a «casa» ideal para seu trabalho de experimentação, ao mesmo tempo que grupo encontrasse a «casa» ideal para seu trabalho de experimentação, ao mesmo tempo que

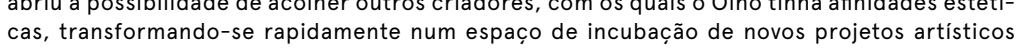
(Vicente, 2017b). Passaram pelo Espaço Ginjal criadores como João Fiadeiro, Miguel Moreira, Ana Borralho, João Galante, Lúcia Sigalho, Francisco Camacho, Paulo Castro, Félix Lozano, Clara Andermatt, Vera Mantero, Alberto Lopes e Edgar Pêra, entre outros. 


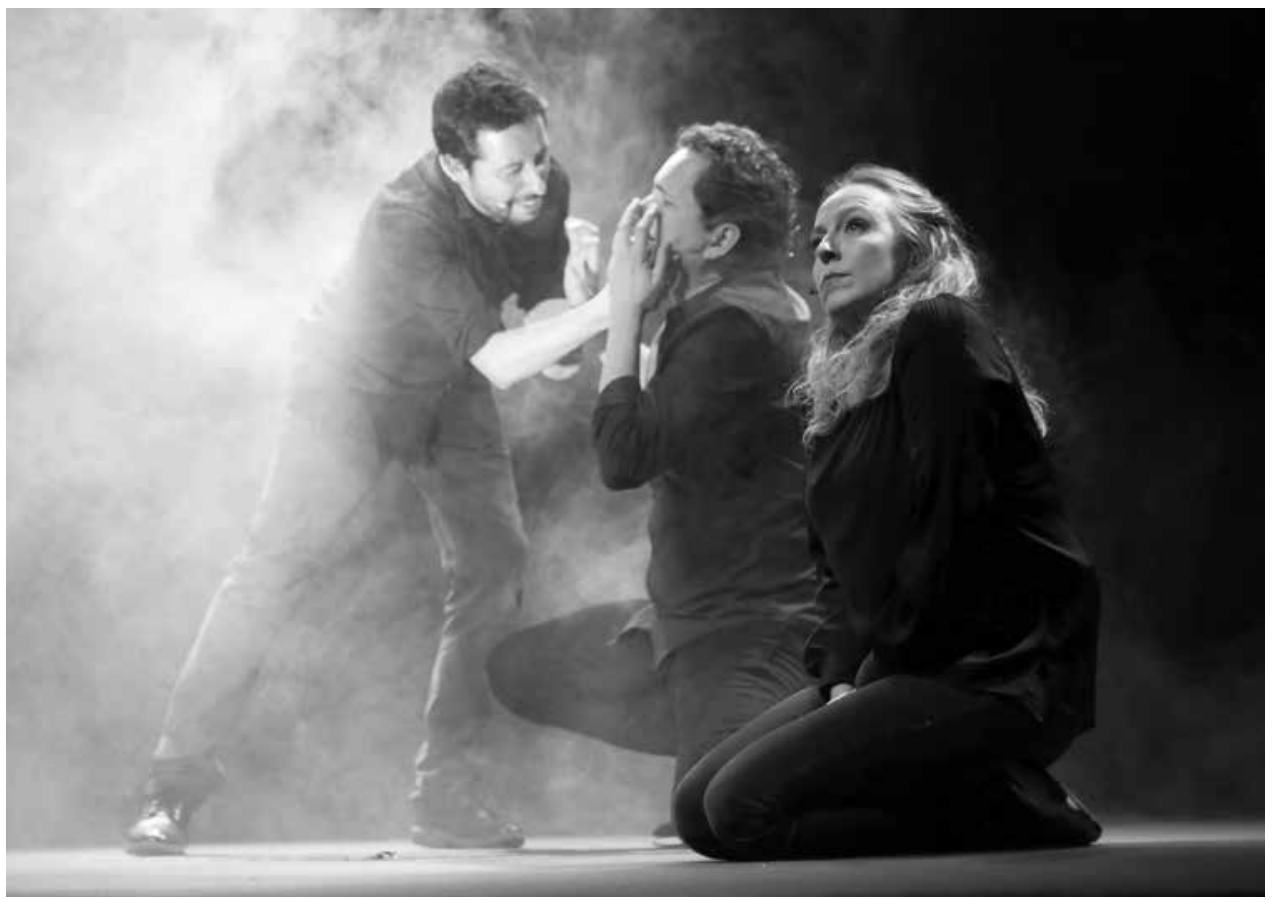

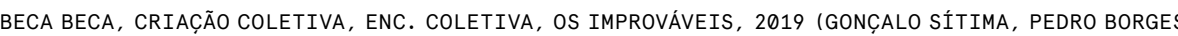
E MARTA BORGES), [F] ZECA CARVALHO

commedia dell'arte, a partir das quais viria a expandir as possibilidades corporais do trabalho de ator; e outros criadores em nome individual como Lúcia Sigalho e Mónica Calle, que, embora com propostas muito diferentes, vieram desvelar a força e a sensibilidade subversiva de um novo sentido do feminino. A Companhia do Chapitô, fundada em 1996, veio reforçar este caminho de transição, contribuindo, a par dos outros grupos da sua geração, para esta mudança de paradigma no teatro. Foi através do trabalho no Chapitô, nomeadamente o realizado com o encenador John Mowat, que se inaugurou, em Portugal, uma verdadeira linha de criação em torno de um teatro físico, especialmente apoiado na improvisação como forma privilegiada de composição cénica, na comédia como veículo de interpelação crítica e no contacto com os espectadores para intensificar a dimensão afetiva do encontro com o público. ${ }^{9}$

9 No site da companhia, pode ler-se: «A Companhia do Chapitô [...] valoriza a comédia pelo seu poder de questionar todos os aspectos da realidade física e social. Cria, desde a sua fundação, espectáculos multidisciplinares assentes no trabalho físico do actor num processo colectivo e em constante desenvolvimento, que convidam à imaginação do público, e que se relacionam estreitamente com este» (https://chapito.org/areas-de-actuacao/cultura/companhia-do-chapito/, consultado em 18 de dezembro de 2019).
Para Graça (2015), os motivos mais significativos pelos quais a cena impro se estabeleceu em Portugal foram a ruptura com as normas do teatro tradicional e a proposta de uma linguagem artística despretensiosa e acessível a um público que estava distante do teatro. Esta transformação foi promovida pela «geração sem fronteiras» da década de 1990, como testemunha o ator-improvisador Ricardo Soares, da companhia Os Instantâneos:

Eu acho que a geração dos anos noventa, parece-me, trazendo o trabaIho da dança, e da experimentação da dança, nos anos noventa... O [encenador] Miguel Moreira, e por aí afora, o Ginjal e tantos mais, acho que foi... deve ter sido, provavelmente, para o teatro de improviso, a [...] primeira força, assim, de improvisação. Depois, tudo isto começa a desvanecer, e então aparece esta zona do Teatro-Desporto... e depois do Teatro-Desporto, então, aparece a improvisação teatral como outra disciplina lateral ao teatro regular. (Soares_Instantâneos)

Pedro Borges, improvisador do coletivo Os Improváveis,, confirma a mesma descendência da «geração sem fronteiras», ainda que estabeleça a ressalva de que os projetos aos quais se dedicavam esses artistas não coincidam completamente com as propostas de teatro de improviso que viriam a ser desenvolvidas nas duas décadas seguintes:

Tive contacto com alguns desses criadores, sim, em workshops diversos. Alguns nomes: Miguel Seabra (Meridional), João Garcia Miguel (Ginjal, Olho), Lúcia Sigalho, Pedro Barão (Inlmpetus), Mónica Calle (Casa Conveniente), João Mota (Comuna), Nuno Pino Custódio (Eira), John Mowatt (Chapitô), Carlos J. Pessoa (Teatro da Garagem) entre muitos outros. E trabalhei quase 10 anos na Cia. A Barraca, com Maria do Céu Guerra. Todos foram importantes no meu desenvolvimento enquanto actor de teatro, embora nenhum apontasse para a criação espontânea improvisada enquanto espectáculo para público. Alguns utilizavam o improviso a partir de texto como forma de encontrar uma cena para fechar, mas não posso dizer que tenha aprendido com eles o tipo de improviso de construção em formato longo que hoje pratico. Aliás, para a grande maioria dos encenadores de teatro, isto ainda é território quase desconhecido. (Borges_Improváveis)

Um dos contributos de fundo da geração de 1990 para o desenvolvimento do teatro de improviso foi a multidisciplinaridade que promoveu 
no seio das artes performativas. Como salienta Madeira (2007), a propósito da influência desta geração, o movimento de renovação teatral no país não se originou a partir de processos criativos que investiam na música para o teatro ou na dança para o teatro, mas de uma remodelação da performance teatral numa conceção alargada de performance enquanto teatro/dança/música. Isto exigia dos performers uma intervenção criativa como atores, dançarinos e cantores, focados na corporalização das suas ideias e não em executar coreografias, com os seus corpos disponíveis para estar e agir, não para dispersamente bailar ou representar. Para Vionnet (2018), essa amplitude técnica é fundamental para um improvisador, na medida em que este utiliza o seu corpo para desenvolver uma criação espontânea: ele precisa de se mover no espaço, pesquisar novas práticas corporais e conquistar uma gestualidade possivelmente desconhecida, e tais são precisamente as potencialidades da dança para a criação cénica.

Outro contributo importante desta geração foi a reconfiguração das formas de relacionamento cénico com os espectadores, que se passaram a apoiar na consideração do público como participante da construção estética do espetáculo. A procura de novas formas de interação com o público resultaria, como argumenta Vicente (2014: 2), no agenciamento de um processo de responsabilização pelos acontecimentos que se sucedem no decurso de uma performance, na qual os espectadores, por intermédio da experiência estética, «são incentivados a dar uma resposta ao experienciado». Esta é uma premissa fundamental para o teatro de improviso, que conta com o público como cúmplice (incontornável) de contracena, sem o qual o acto da improvisação não pode ocorrer, no sentido total do termo.

\section{A COMPANHIA DO CHAPITÔ E SUA INFLUÊNCIA}

\section{NO DESENVOLVIMENTO DO TEATRO DE IMPROVISO}

A Companhia do Chapitô nasceu em 1996 no seio da instituição com o mesmo nome (Chapitô - Colectividade Cultural e Recreativa de Santa Catarina) fundada em 1981 por Teresa Ricou, com o intuito de promover uma forma alternativa de educação pela arte. Inspirada pelas correntes do Novo Circo despontadas anos antes no panorama internacional, a instituição cedo investiu na formação através da criação da Escola Profissional de Artes e Ofícios do Espectáculo (EPAOE). Esta escola viria a apostar numa nova linha de formação do ator em Portugal, apoiada nas técnicas circenses - muito especialmente o clown - e na corporalidade como formas centrais de habilitação performática. Muitos dos atores que viriam, posteriormente, a integrar o elenco da companhia foram formados nesta escola. Não é, pois, de estranhar que, desde a sua fundação, a Companhia do Chapitô vem mantendo, como atesta André Paes Leme, «um ininterrupto processo de produção de espectáculos nos quais a comédia, o improviso, a gestualidade, o clown e o épico se encontram entre as linhas primordiais das suas criações» (2008: 6). Para isto muito contribuiu o encenador britânico John Mowat $^{10}$, que, convidado inicialmente para dar aulas na EPAOE, acabou a dirigir a Companhia do Chapitô, imprimindo o tom estético que viria a ser a marca distintiva do grupo. Como recorda Leme (2008), este encenador sempre se interessou pela proposta física da cena, baseando-se no desenvolvimento da espontaneidade dos atores como pilar essencial da presença cénica. A propósito da histórica montagem de D. Quixote em 2002, o mesmo autor reforça ainda a ênfase dada por Mowat à improvisação como «ferramenta principal tanto no processo de construção do espectáculo quanto nas suas apresentações» (idem: 22), elegendo «como foco central a poética produzida pelo corpo do actor» (idem: 88 ).

Ricardo Peres, César Mourão e Carlos M. Cunha foram formados em artes e animação circense pela EPAOE, e vieram a ser os pioneiros do teatro de improviso em Portugal, fundando a companhia Commedia a la Carte em 200o - grupo que permanece, ainda hoje, como o nome mais sonante da cena impro portuguesa. ${ }^{11}$ Nesse mesmo ano, sem referências anteriores no país - apenas com o suporte de alguns livros sobre impro e a partir de algumas noites de experimentações com base no que aprenderam no Chapitô -, os três levaram a palco, pela primeira vez, uma improvisação como espetáculo, na vertente de jogos curtos, nos quais prevalecia o tom humorístico das suas apresentações. Nos anos seguintes, o grupo promoveu competições de teatro-desporto entre comediantes sem formação em impro, que viriam a revelar-se fundamentais para a popularização do género em Portugal.

10 Formado em escultura, John Mowat ingressou no teatro em 1980, levando as suas performances a mais de quarenta países. A partir de 1990, começou a dedicar-se mais ao ensino, realizando diversos workshops em escolas de teatro, dança e música. Foi neste contexto que foi professor convidado na EPAOE e, mais tarde, encenador da Companhia do Chapitô (Leme, 2008).

11 A formação atual do grupo Commedia a la Carte conta com o ator, académico e encenador colombiano Gustavo Miranda no lugar de Ricardo Peres. 
Em 2008 e 2011, respetivamente, nasceram os dois outros coletivos que, juntamente com o Commedia a la Carte, constituem atualmente as três maiores companhias profissionais de impro em Portugal: Os Improváveise Instantâneos. Sob a direção de Sanne Leijenaar ${ }^{12}$, Os Improváveis foram o primeiro grupo português a pesquisar os formatos longos de impro, a procurar formação especializada no estrangeiro e a representar Portugal em festivais internacionais. Dois dos membros do grupo Os Improváveis - Marta Borges e Pedro Borges - foram, também eles, atores submetidos a formações profissionais ministradas pelo diretor John Mowat. Os Instantâneos surgiram igualmente pela mão de atores com passagem pelo Chapitô, tendo formado o grupo na sequência de um treino especializado com Pablo Pundik - improvisador argentino radicado em Madrid, onde dirige o Teatro Asura e participa do coletivo Impromadrid. Foram eles a implementar, pela primeira vez em Portugal, um espetáculo no qual atores com formação específica na área da improvisação se apresentavam num formato competitivo.

Entre os anos de 2012 e 2015, a partir de cursos ou projetos paralelos conduzidos pelos coletivos Instantâneos e Os Improváveis, surgiram diversos grupos de impro que, na sua maioria, foram sendo extintos. São poucos os coletivos remanescentes que mantêm uma produção artística regular, destacando-se, pela sua continuidade criativa, os Improv FX, Improvisto, Cardume e Sem Rede.

Pode afirmar-se, assim, que uma parte significativa dos improvisadores portugueses deriva direta ou indiretamente da estética singular da Companhia do Chapitô, na qual o trabalho sobre o corpo recebe uma forte influência da prática circense e da disciplina do clown promovida na EPAOE e onde a improvisação ocupa um lugar de destaque nos processos criativos. A Companhia do Chapitô sempre instigou nos seus atores a capacidade de jogar «constantemente com os incidentes do improviso a seu favor, usando a comédia como instrumento para questionar os aspectos da realidade física e social», como realça Casals (2012: 23-24). Dias (2013) também reforça o caráter pioneiro e a originalidade da Companhia em relação ao género que o seu diretor John Mowat denomina «comédia física» ou «comédia visual» - a qual comporta um amplo universo baseado nas disciplinas da palhaçaria, da mímica e da commedia dell'arte-,

12 Depois de uma estadia de quase dois anos no Brasil, onde trabalhou como dramaterapeuta num projeto patrocinado pelo UNICEF para crianças em situação de vulnerabilidade social, a diretora teatral, pedagoga e terapeuta holandesa Sanne Leijenaar estabeleceu-se em Lisboa no início de 2007. Entre junho de 2008 e dezembro de 2010, foi a diretora do grupo Os Improváveis, tendo enfatizado o treino dos performers em técnicas de teatro-desporto.

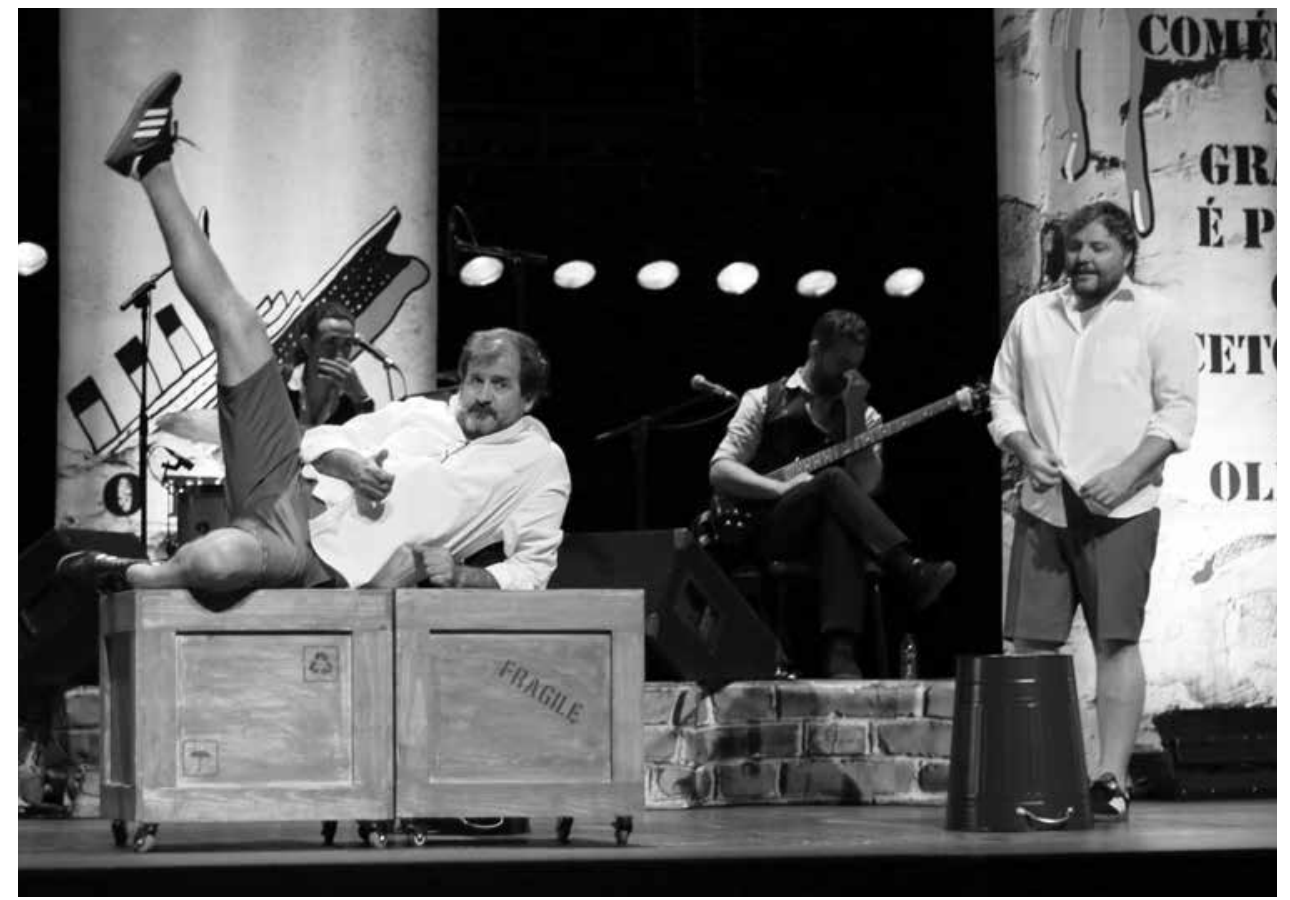

D PIOR ESPETÁCULO DO MUNDO, CRIAC̄̃̃ COLETIVA, ENC. COLETIVA, COMMEDIA A LA CARTE, 2019 (CARLOS M. CUNHA E CÉSAR MOURÃO), [F] ZECA CARVALHO

engendrando uma linguagem pouco explorada em Portugal. A autora mapeia esse estilo insólito de comédia como um teatro de ações físicas, em que a palavra pode ou não ser usada, e no qual textos clássicos ou originais podem ser gerados ou adaptados por intermédio da improvisação.

Em entrevista a Carlos M. Cunha, da Commedia a la Carte, o improvisador confirma esta descendência artística, creditando ao jogo improvisado a partir do corpo, proposto pelo encenador John Mowat no âmbito das suas criações na Companhia do Chapitô, parte da responsabilidade pela maneira como se encetou e desenvolveu o teatro de improviso em Portugal:

Num espetáculo com dois meses de ensaios, com o John [Mowat], o primeiro mês é brincar. É jogo, jogo, jogo, jogo, jogo. [...] E isso tudo foi ouro para mim. Tudo isso [...] era um jogo físico. [...] Teatro físico, teatro de gesto. Somente. [...] É toda uma nova linguagem. É o bufão com... dança, com aquilo que tu sentes. Viver dentro, descobrir. O John trouxe uma nova linguagem. [...] Ele, por exemplo, tinha coisas do género... sentava-se e dizia: «Faz-me rir. OK. Saiam da sala. Tu ficas aqui. És uma pulga e isto 
é um cão. E eles vão entrar, um de cada vez, e vão tentar descobrir o que é que tu és.» [...] E depois, alguém que entra tem de assumir que sabe perfeitamente onde é que está, o que está a acontecer, e que está completamente identificado com aquele que lá está. [...] Isso é improviso. Completo. Só improviso. Isso é uma grande escola, porque te dá grande disponibilidade mental e física. (Cunha_Commedia)

A propósito da influência particular das técnicas circenses no Chapitô, Kasper (2011: 88) relembra o complexo processo de construção do clown nas artes cénicas, realçando que «aos corpos clownescos é permitido - e desejável-improvisar», ou seja, «aprender a abrir-se para escutar e atuar com o que está de fora», pois o jogo do palhaço «só funciona quando envolve o outro». No depoimento seguinte, Cunha descreve o momento exato da descoberta de «seu» clown, momentos antes de um espetáculo no Chapitô. Em vez de se apresentar no palco com os outros atores, Cunha percebeu que o seu palhaço precisava de interagir, não com os outros artistas, mas com os próprios espectadores, e dessa ideia nasceu um clown que trabalhava como empregado de mesa na esplanada da companhia de teatro, com o qual improvisava números de plateia.

Eu fui ao camarim, ao guarda-roupa... e trouxe camisa branca, um laço, um paletó de chefe de sala de empregados de mesa, calças pretas ligeiramente subidas, meia branquinha. Clown! Mas um clown muito... uns óculos! E fiz uma coisa que eu via na minha aldeia, que era... quando os óculos partiam, eles não tinham dinheiro para mandar arranjar, então punham um fio, daqueles de coser os botões, assim, à volta. E deixei um pedacinho assim, pendurado. Tanta gente, tantas vezes, me dizia: «Olha, o senhor tem um...» e eu sabia que aquilo estava lá exatamente para as pessoas me dizerem isto. E eu peguei naquilo e pus-me dentro da tenda de circo que dá para a esplanada [do restaurante do Chapitô] [...] E eu estive aí meia hora a ganhar coragem, com a bandeja, ou seja, eu vou ser um empregado de mesa na esplanada. Mas eu não sabia nada. Como é que eu ia andar, como é que eu ia falar, como é que eu ia... nada. Estive ali meia hora atrás da porta. Até que senti uma coisa a fazer assim [gesto de empurrar]. E quando eu entro na esplanada, daqui para aquela parede [aponta], eu descobri o andar, o olhar, a maneira de falar e as atitudes dele. (Cunha_Commedia)

Frost e Yarrow (2015) compreendem que, em termos de performatividade, o clown predispõe o ator a operar de maneira harmónica com certos processos criativos que podem ser encontrados em algumas vertentes do teatro de improviso, nomeadamente no que se refere à sua habilidade para contradizer comportamentos esperados, quebrar tabus e libertar-se de narrativas mecanizadas. Para os autores, a natureza disruptiva do clown conduz o artista a trabalhar a partir da falha, da surpresa, dos mal-entendidos, dos acidentes e da constante transformação, exatamente como se espera de um improvisador. Desta perspetiva, torna-se fácil perceber o quão marcante foi para o desenvolvimento dos improvisadores portugueses a sua passagem pela Companhia do Chapitô - em cujo trabalho a arte do palhaço (promovida desde o início por Teresa Ricou) ${ }^{13}$ sempre contagiou os processos criativos.

Pedro Borges destaca, em particular, os projetos realizado sob a direção de John Mowat, e a importância do seu trabalho para o que se veria a seguir nos grupos de impro em Portugal.

Eu não fiz parte da Companhia do Chapitô, mas fiz alguns workshops com o John Mowat, o encenador da altura. Ele era muito original, as suas criações de teatro físico eram incríveis, usavam muitas técnicas que hoje se usam frequentemente num espectáculo de improviso (mudanças de espaço, utilização de objectos para criar tudo, desdobramento de personagens pelo mesmo actor, jogar com personagem invisível etc.). Foi importante ter contacto com essa realidade. (Borges_Improváveis)

Se a EPAOE habilitou os futuros improvisadores para um trabalho centrado no corpo-especialmente o que se manifesta através das técnicas circenses, no geral, e da exploração da figura do clown, em particular foi na Companhia do Chapitô (principalmente pela mão de Mowat) que estes atores conseguiram ampliar as suas aptidões ao serviço de um teatro físico, no qual a improvisação sempre foi um fator incontornável.

\section{CONSIDERAÇÕES FINAIS}

Esta investigação foi norteada pelo objetivo de analisar a genealogia do teatro de improviso em Portugal, tendo-se conseguido estabelecer uma

13 Teté, a mulher palhaço, é a personagem clownesca construída por Teresa Ricou, mantendo-se como figura de grande importância para a cultura circense em Portugal. A sua formação foi
marcada pelas passagens no Thêatre du Soleil, sob a orientação de Ariane Mnouchkine, e na escola de Jacques Lecoq, onde pôde aprofundar os seus conhecimentos sobre o trabalho corporal (Leme, 2008). 
correlação com o movimento de renovação artística promovido pela geração de 1990. Não se pode deixar de mencionar, no entanto, que os formatos teatrais firmados a partir da improvisação descendem, no geral, da commedia dell'arte (Fotis, 2012; Muniz, 2015), que emergiu no século XVI na Europa, e que também recebeu a nomenclatura de commedia all'improviso, atingindo o seu auge nos finais do século XVII e ao longo do século XVIII. No contexto teatral português, o desenvolvimento deste género teatral terá sofrido, desde então, múltiplas influências que, de alguma forma, contribuíram para a cultura de improvisação que se viria a manifestar, de forma mais evidente, a partir dos anos noventa e que estão ainda por explorar de forma aprofundada. O teatro de revista, por exemplo - presente de forma regular desde meados do século XIX em Portugal -, sempre cultivou uma predisposição performática para o improviso, decorrente do contacto promovido com o público e do tom provocador dos seus números - especialmente os ligados aos comentários da atualidade política e social. ${ }^{14}$

Da geração de 1990, o Chapitô foi a companhia que mais contribuiu para a promoção do teatro de improviso, uma vez que acolheu e formou a grande maioria dos seus pioneiros - precisamente sete dos dez integrantes dos primeiros três grupos de impro nascidos em Portugal ${ }^{15}$, como evidencia o relato de Pedro Borges, do coletivo Os Improváveis, reconhecendo que, em termos técnicos, foi a Companhia do Chapitô que dotou um número significativo de atores das competências performativas necessárias para que o género pudesse florescer em Portugal.

$\mathrm{Em}$ anos vindouros, o desenvolvimento do género impro em Portugal, cujo espetáculo inaugural ocorreu somente há duas décadas, revelará até que ponto os improvisadores portugueses herdaram da geração de 1990 apenas a ruptura com os cânones estéticos até então estabelecidos ou se, através da sua prática continuada, também eles virão a abrir novas possibilidades artísticas. Especialmente as que se formam no diálogo entre o teatro e a política, que as improvisações baseadas na vida quotidiana quase sempre desencadeiam, evocando fantasmas, convocando tensões, revelando preconceitos e outras formas de relação com a atualidade que, cada vez menos, passam despercebidas na esfera pública.

14 Cf. Rebello (1984) e Cruz (2014).

15 São eles: Carlos M. Cunha, César Mourão e Ricardo Peres, do grupo Commedia a la Carte; Marta Borges e Pedro Borges, do coletivo Os Improváveis; e Marco Graça e Ricardo Soares, dos Instantâneos.

\section{REFERÊNCIAS BIBLIOGRÁFICAS}

BRILHANTE, M. (2009), «Laços e desenlaces entre criação e reflexão crítica no teatro português contemporâneo», Sala Preta, 9 (1), pp. 121-132.

CASALS, D. (2012), O Chapitô, criação e criador da educação pelas artes em Portugal, dissertação de mestrado em Práticas Culturais apresentada à Faculdade de Ciências Sociais e Humanas da Universidade Nova de Práticas
Lisboa.

COELHO, R. P. (2017), «Experimentalismo, Política e Utopia: Um teatro português do início do século xx ao dealbar do novo milénio», in Rui Pina Coelho (ed.), Teatro português contemporâneo: Experimentalismo, Politica e Utopia [título provisório], Lisboa, TNDMII/Bicho do Mato, pp. 23-39.

CRUZ, D. I. (2014), «O teatro de revista em Portugal (I)» in Raiz e Utopia, Centro Nacional de Cultura, disponivel em https://e-cultura.blogs.sapo.pt/o-teatro-de-revista-em-portugal-i-299708, consultado em 18 de dezembro de 2019 .

DIAS, M. (2013), Comédia física: the playful actor, dissertação de mestrado em Artes Performativas apresentada à Escola Superior de Teatro e Cinema do Instituto Politécnico de Lisboa.

DUDECK, T. (2013), Keith Johnstone: a critical biography, Londres, Bloomsbury Methuen Drama.

FOTIS, M. (2012), The Harold: a revolutionary form that changed improvisational theatre \& american comedy, tese de doutoramento em Filosofia apresentada ao Departamento de Teatro da Universidade do Missouri, Estados Unidos.

FROST, A., e YARROW, R. (2015), Improvisation in drama, theatre and performance: history, practice, theory, $3 .{ }^{\mathrm{a}} \mathrm{ed}$. , Basingstoke, Palgrave Macmillan.

GIL, J. (2007), Portugal, hoje: o medo de existir, Lisboa, Relógio D’Água.

GRACA, M. (2015), «En la impro construimos una verdad invisible», entrevista a Feña Ortalli, Status - Revista de Impro, 4 (47).

JOHNSTONE, K. (1990), Impro-la improvisación y el teatro, Santiago, Cuatro Vientos.

KASPER, K. (2011), «Dos corpos sentados aos gestos em fuga: estatutos dos corpos em processos de formação», Revista da Faculdade de Educação, IX (15), pp. 79-95.

LEME, A. (2008), D. Quixote - uma dupla paródia nas mãos do Chapitô, dissertação de mestrado em Estudos de Teatro apresentada à Faculdade de Letras da Universidade de Lisboa.

MADEIRA, C. (2007), O hibridismo nas artes performativas em Portugal, tese de doutoramento em Ciências Sociais apresentada ao Instituto de Ciências Sociais da Universidade de Lisboa.

MUNIZ, M. (2015), Improvisação como espetáculo: processo de criação e metodologias de treinamento do ator-improvisador, Belo Horizonte, Editora UFMG.

ORTALLI, F. (2014), «Opinión: nuevos espacios, nuevas propuestas», Status - Revista de Impro, 3 (34).

REBELLO, L. F. (1984), História do Teatro de Revista em Portugal (Volumes 1 e 2), Lisboa, Publicações Dom Quixote. SAMPIERI, R., COLLADo, C., e LuCIO, P. (2015), Metodologia de pesquisa, 5. a ed., São Paulo, McGraw-Hill.

SWIBODA, M. (2018), «Improvisation in disruptive times», Liminalities: A Journal of Performance Studies, 14 (1), pp. 41-71.

VICENTE, G. (2017a), «Introduction: the urge to embody the world» in Gustavo Vicente (ed.), Intensified bodies from the performing arts in Portugal, Berna, Peter Lang, pp. 1-15.

- (2017b), «Bases de criação para o século xxı: a intensificação da experiência cénica em João Garcia Miguel (O Olho) e em Miguel Moreira (Útero)», in Rui Pina Coelho (ed.), Teatro português contemporâneo: Experimentalismo, Política e Utopia [título provisório], Lisboa, TNDMII/Bicho do Mato, pp. 23-39.

- (2014), «É-ti-quê», ESC:ALA Revista Electrónica de Estudos e Práticas Interartes, 1, pp. 1-6.

- (2012), «Geração sem fronteiras», Sinais de Cena, 17, pp. 70-78.

VIONNET, C. (2018), L'Ombre du geste: le(s) sens de l'expérience en danse contemporaine, tese de doutoramento em Ciências Sociais apresentada à Faculdade de Ciências Sociais e Políticas da Universidade de Lausana, Suíça. 


\section{ZECA CARVALHO}

Actor, director, bacharel em Artes Cénicas, mestre e doutor em Administração, professor associado da Universidade Federal do Rio de Janeiro e investigador de pós-doutoramento no Centro de Estudos de Teatro da Universidade de Lisboa.

\section{GUSTAVO VICENTE}

Professor, investigador, ator e encenador. Professor na Faculdade de Letras da Universidade de Lisboa e investigador do Centro de Estudos de Teatro, onde coordena a linha de investigação Discursos Críticos em Artes Performativas. 